American Journal of Applied Sciences 9 (4): 492-495, 2012

ISSN 1546-9239

(C) 2012 Science Publications

\title{
The Mathematical Model and Simulation of Thyristor Controlled Series Capacitor in Medium Transmission Line
}

\author{
Prechanon Kumkratug \\ Division of Electrical Engineering, Faculty of Engineering at Si Racha, \\ Kasetsart University, 199 M.6, Tungsukhla, Si Racha, Chonburi, 20230, Thailand
}

\begin{abstract}
Problem statement: It is becoming increasingly important to fully utilize the existing transmission system assets due to environmental legislation, rights-of-way issues, costs of construction and deregulation policies that introduced in recent years. The Thyristor Controlled Series Capacitor (TCSC) has been proposed for the better control power flow and dynamic performance. The exact medium transmission line model consists of the resistance and reactance. Most of previous researches studies transient stability performance of the TCSC in SMIB System with neglecting the resistance of the line. Thus the fully capability of the TCSC on transient stability improvement of power system may not be applied. The consideration of the resistance causes in the difficulty of deriving the mathematical model. Approach: This study investigates the effect of the TCSC on transient stability of the power system with consideration the exact medium transmission line mode. The concept of two-port network is applied to simplify the mathematical model of the power system. The proposed method is tested on sample system and compared on various cases. Results: The first swing of rotor angle curve of the faulted system without resistance is obviously higher than that of with resistance whereas the second swing of the faulted system without resistance is slightly less than that of with resistance. The system with a TCSC can improve transient stability of power system. Conclusion: It was found from this study that the TCSC and resistance of the line can improve first swing of rotor angle. However, the resistance of the line provides the negative effect on second swing of rotor angle. The simulation results indicate that for practical medium line, the resistance is very import parameters for evaluating transient stability of power system.
\end{abstract}

Key words: Power system stability, transient stability, critical clearing time, FACTS devices, resistance, reactance, capacitance, transmission line, medium transmission line, two-port network

\section{INTRODUCTION}

Nowadays, the demand of electricity has dramatically increased and a modern power system becomes a complex network of transmission lines interconnecting the generating stations to the major loads points in the overall power system in order to support the high demand of consumers. It is becoming increasingly important to fully utilize the existing transmission system assets due to environmental legislation, rights-of-way issues, costs of construction and deregulation policies that introduced in recent years. A number of Flexible AC Transmission System (FACTS) controllers, based on the rapid development of power electronics technology, have been proposed for better utilization of the existing transmission systems (Magaji and Mustafa, 2009; Prechanon, 2010; Zarate-Minano et al., 2010; Omar et al., 2010; Padma and Rajaram, 2011).
The Thyristor Controlled Series Capacitor (TCSC) is the series FACTS devices. It consists of the capacitor bank reactor bank and thyristor. The thyristors control the reactance or susceptance that dictates the power flow through a line as shown in Fig. 1. The TCSC can be applied for improving transient stability of power system (Li et al., 2010).

The evaluation of Critical Clearing Time (CCT) of power system is one of the most important research areas for power engineers because it indicates the robustness of the faulted power system.

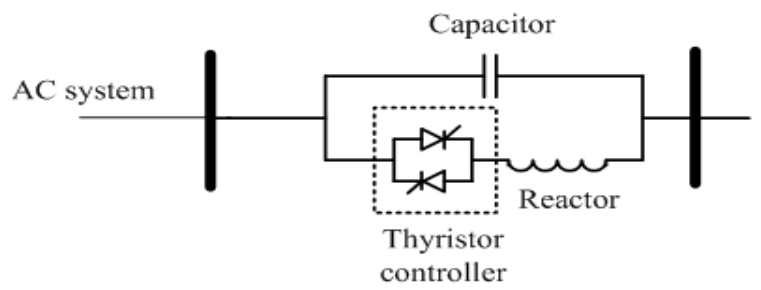

Fig. 1: Schematic diagram of TCSC 
The rotor angle of the synchronous generator determines the stability of power system. Although the stability of the synchronous machine is used to represent the stability of the power system, all of the power system components such as transmission line and transformer affect the stability of the power system.

The transmission line is one of the most important parts in power system components. Most of the fault occurs at the transmission line. The transmission line is generally divided into three major categories; short, medium and long model whose distance are about 80 $\mathrm{km}$, above $80-250 \mathrm{~km}$ and above $250 \mathrm{~km}$, respectively. Many previous researches used simple transmission line model by neglecting its resistance or capacitance. To fully utilization the existing system, the exact transmission line should be further investigated.

This study will investigate the capability of the TCSC on transient stability of the SMIB system with the exact medium transmission line model. The concept of two-port network is applied to simplify the mathematical model of the power system. The sample system consisting the practical medium transmission line is used to investigate in this study. The proposed method is tested on various cases.

\section{MATERIALS AND METHODS}

Mathematical model: Figure 2a shows the single line diagram of power system consisting of a generator, a transformer, four medium transmission lines and TCSC. Figure $2 b$ shows the equivalent of Fig. $2 a$. The generator is represented by a synchronous voltage in quadrature axis $\left(\mathrm{E}_{\mathrm{q}}^{\prime}\right)$ behind direct transient reactance $\left(\mathrm{X}_{\mathrm{d}}{ }_{\mathrm{d}}\right)$. The $\mathrm{V}_{\mathrm{b}}$ is the voltage at infinite bus. The exact medium transmission line model is represented by the impedance $\left(\mathrm{Z}_{\mathrm{L}}\right)$ which consists of a resistance $\left(\mathrm{R}_{\mathrm{L}}\right)$ and reactance $\left(\mathrm{X}_{\mathrm{L}}\right)$. The TCSC can be modeled as the variable shunt susceptance $\left(\mathrm{X}_{\mathrm{TCSC}}\right)$ as shown in Fig. 2b. This study will apply the concept of the two-port network to simplify the equivalent in Fig. $2 b$. Each component of power system and a TCSC can be represented the matrix of two-port networks (A, B, C and D) as shown in Fig. 2c and given by Eq. 1-8:

$$
\begin{aligned}
& \mathrm{A}_{1}=\mathrm{A}_{2}=\mathrm{A}_{3}=\mathrm{A}_{4}=\mathrm{A}_{5}=\mathrm{A}_{6}=\mathrm{A}_{\text {TCSC }}=1 \\
& \mathrm{~B}_{1}=\mathrm{j} \mathrm{X}_{\mathrm{d}}^{\prime} \\
& \mathrm{B}_{2}=\mathrm{j} \mathrm{X}_{\mathrm{t}}^{\prime} \\
& \mathrm{B}_{3}=\mathrm{B}_{4}=\mathrm{B}_{5}=\mathrm{B}_{6}=\mathrm{j} \mathrm{Z}_{\mathrm{L}} \\
& \mathrm{B}_{\text {TCSC }}=-\mathrm{j} \mathrm{X}_{\mathrm{TCSC}}
\end{aligned}
$$

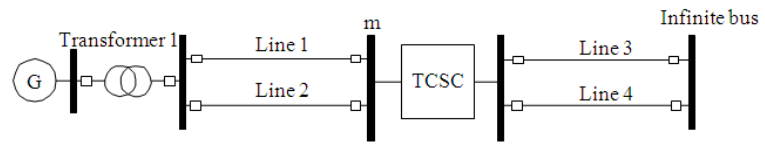

(a)

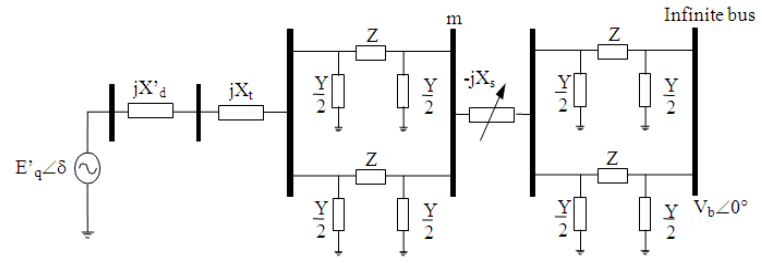

(b)

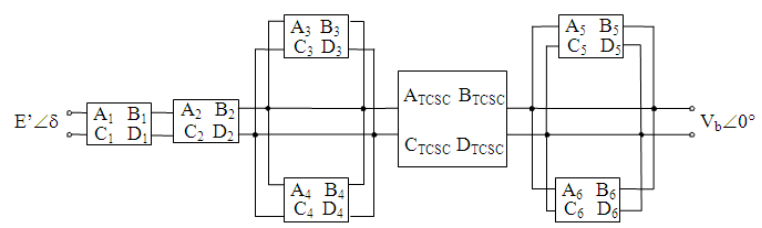

(c)

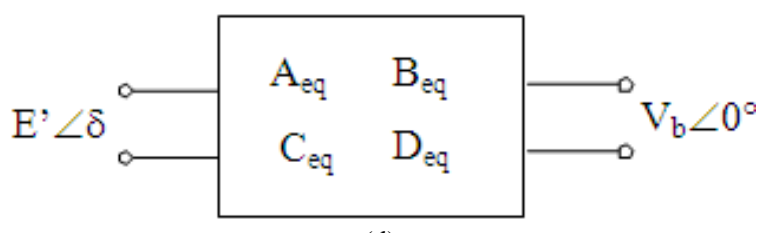

(d)

Fig. 2: Single machine infinite bus system with a TCSC (a) schematic diagram (b) equivalent circuit (c) two-port networks diagram (d) the net two-port network

$\mathrm{C}_{1}=\mathrm{C}_{2}=\mathrm{C}_{3}=\mathrm{C}_{4}=\mathrm{C}_{5}=\mathrm{C}_{6}=0$

$\mathrm{C}_{\mathrm{TCSC}}=0$

$\mathrm{D}_{1}=\mathrm{D}_{2}=\mathrm{D}_{3}=\mathrm{D}_{4}=\mathrm{D}_{5}=\mathrm{D}_{6}=\mathrm{D}_{\mathrm{TCSC}}=1$

It can be seen from the Fig. 2c that some ports are in series and in shunt connection. For example, a port 1 and port 2 are in series connection whereas port 3 and port 4 are in shunt connection. Thus with the series combination of port 1 and port 2, a new port is given by Eq. 9-12:

$$
\begin{aligned}
& \mathrm{A}_{\mathrm{s}}=\mathrm{A}_{1} \mathrm{~A}_{2}+\mathrm{B}_{1} \mathrm{C}_{2} \\
& \mathrm{~B}_{\mathrm{s}}=\mathrm{A}_{1} \mathrm{~B}_{2}+\mathrm{B}_{1} \mathrm{D}_{2} \\
& \mathrm{C}_{\mathrm{s}}=\mathrm{A}_{2} \mathrm{C}_{1}+\mathrm{C}_{2} \mathrm{D}_{1} \\
& \mathrm{D}_{\mathrm{s}}=\mathrm{B}_{2} \mathrm{C}_{1}+\mathrm{D}_{1} \mathrm{D}_{2}
\end{aligned}
$$


Similarly, with the shunt combination of port 3 and port 4, a new port is given by Eq. 13-16:

$$
\begin{aligned}
& \mathrm{A}_{\mathrm{sh}}=\left(\mathrm{A}_{3} \mathrm{~B}_{4}+\mathrm{A}_{4} \mathrm{~B}_{3}\right) /\left(\mathrm{B}_{3}+\mathrm{B}_{4}\right) \\
& \mathrm{B}_{\mathrm{sh}}=\mathrm{B}_{3} \mathrm{~B}_{4} /\left(\mathrm{B}_{3}+\mathrm{B}_{4}\right) \\
& \mathrm{C}_{\mathrm{sh}}=\mathrm{C}_{1}+\mathrm{C}_{2}+\left(\mathrm{A}_{1}-\mathrm{A}_{2}\right)\left(\mathrm{D}_{2}-\mathrm{D}_{1}\right) /\left(\mathrm{B}_{1}+\mathrm{B}_{2}\right) \\
& \mathrm{D}_{\mathrm{sh}}=\left(\mathrm{B}_{4} \mathrm{D}_{3}+\mathrm{B}_{3} \mathrm{D}_{4}\right) /\left(\mathrm{B}_{3}+\mathrm{B}_{4}\right)
\end{aligned}
$$

With the above concepts, the net two-port network diagram is shown in Fig. $2 d$. Here $A_{\text {eq }}, B_{\text {eq }}, C_{e q}$ and $D_{\text {eq }}$ are the element in net matrix of net two-port networks.

The output electrical power of synchronous machine $\left(\mathrm{P}_{\mathrm{e}}\right)$ :

$P_{e}=\frac{A_{e q}\left(E_{q}^{\prime}\right)^{2}}{B_{\text {eq }}} \cos \left(\theta_{\text {Beq }}-\theta_{\text {Aeq }}\right)-\frac{V_{b} E_{q}^{\prime}}{B_{\text {eq }}} \cos \left(\theta_{\text {Beq }}+\delta\right)$

Here:

$$
\mathrm{A}_{\text {eq }}=\mathrm{A}_{\text {eq }} \angle \theta_{\text {Aeq }} \mathrm{B}_{\text {eq }}=\mathrm{B}_{\text {eq }} \angle \theta_{\text {Beq }}
$$

The dynamic equation for evaluating critical clearing tine of the system in Fig. $2 \mathrm{a}$ is given by:

$\dot{\delta}=\omega$

$\dot{\omega}=\frac{1}{\mathrm{M}}\left[\mathrm{P}_{\mathrm{m}}-\mathrm{P}_{\mathrm{e}}\right]$

Here, $\delta, \omega$ and $\mathrm{P}_{\mathrm{m}}$ as given in Eq. 18-19 are the rotor angle, speed, mechanical input power and moment of inertia, respectively of synchronous machine. The $\mathrm{P}_{\mathrm{e}}$ is the output electrical power of synchronous as given in Eq. 17.

It can be mentioned here that the variable shunt susceptance of the TCSC as given in Eq. 7 is changed during the dynamic state for improve the transient stability. This study uses the linear control given by Eq. 20:

$$
\mathrm{X}_{\mathrm{TCSC}}=\mathrm{K} \omega
$$

Here $\mathrm{K}$ is the constant gain control.

\section{RESULTS}

The proposed mathematical model is tested on the sample system. Consider the diagram of sample system is shown in Fig. 1a. The system data are:
Generator:

$\mathrm{H}=5, \mathrm{X}_{\mathrm{t}}=0.1 \mathrm{pu}, \mathrm{X}_{\mathrm{d}}{ }=0.20 \mathrm{pu}, \mathrm{E}_{\mathrm{q}}=1.22 \angle 31.64 \mathrm{pu}$

Transmission line data: voltage level $345 \mathrm{kV}, 130$ $\mathrm{km}, \mathrm{f}=50 \mathrm{~Hz}, \mathrm{R}=0.036 \Omega \mathrm{km}^{-1}, \mathrm{~L}=0.8 \mathrm{mH} \mathrm{km}{ }^{-1}, \mathrm{C}$ $=0.0112 \mu \mathrm{F} \mathrm{km} \mathrm{km}^{-1}$. Thus the impedance $(\mathrm{Z})$ and the admittance (Y) of the medium line at fundamental frequency are $\mathrm{Z}=4.68+\mathrm{j} 32.6726 \mathrm{ohm}$ and $\mathrm{Y}=0+\mathrm{j}$ 0.000457416 Siemens, respectively. The percentage of $\mathrm{R} / \mathrm{X}$ and $\mathrm{B}_{\mathrm{c}} / \mathrm{X}$ of the line are $=14.32 \%$ and $\mathrm{B}_{\mathrm{c}} / \mathrm{X}=$ $0.0014 \%$, respectively. With the given reactance of the line $(X)=0.5 \mathrm{pu}$, the per unit of $\mathrm{R}$ and $\mathrm{B}_{\mathrm{c}}$ are 0.0716 and $7 \times 10^{-6} \mathrm{pu}$, respective.

It is considered that three phase fault appears at line 1 near bus $\mathrm{m}$ and the fault is cleared by opening circuit breakers at the end of the line. Figure 3 shows the rotor angle of the system without a TCSC $(\mathrm{K}=0)$ for clearing time $\left(\mathrm{t}_{\mathrm{cl}}\right)$ for $170 \mathrm{msec}$. The maximum and minimum rotor angle with $\mathrm{R} / \mathrm{X}=0$ are 107.80 and 0.63 degree, respectively. The maximum and minimum rotor angle with $\mathrm{R} / \mathrm{X}=14.32 \%$ are 103.74 and -2.77 degree, respectively. Table 1 shows the rotor angle of the system with a TCSC $(\mathrm{K}=10)$ and with the $\mathrm{R} / \mathrm{X}=14.32 \%$.

The critical clearing time of the system without FACTS devices and with R/X $14.32 \%$ are around 209210 , msec. Figure 4 shows the swing curve of the system with a various gains of a TCSC equipped in the exact medium transmission line model. Table 2 summarizes the values of the maximum and minimum rotor angles of Fig. 4.

Table 1: The maximum and minimum rotor angle of the system with a TCSC and various parameters of the medium transmission line

\begin{tabular}{lllll}
\multicolumn{2}{c}{ line } & & \\
\hline CASE & $\mathrm{R}$ & $\mathrm{B}_{\mathrm{c}}$ & $\delta_{\max }($ degree $)$ & $\delta_{\min }($ degree $)$ \\
\hline 1 & 0.0000 & 0 & 94.60 & 12.92 \\
2 & 0.0716 & 0 & 92.48 & 12.20 \\
3 & 0.0000 & $7 \times 10^{-6}$ & 94.60 & 12.92 \\
4 & 0.0716 & $7 \times 10^{-6}$ & 92.48 & 12.20 \\
\hline
\end{tabular}

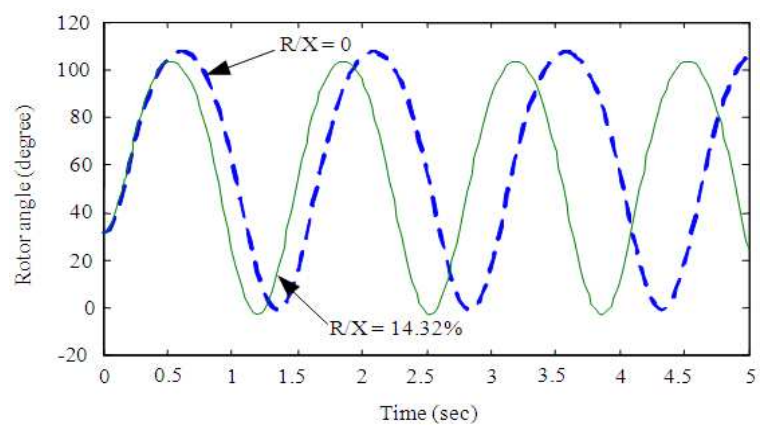

Fig. 3: The swing curve of the system without FACTS devices for tcl $=170 \mathrm{~m} \mathrm{sec}$ 
Am. J. Applied Sci., 9 (4): 492-495, 2012

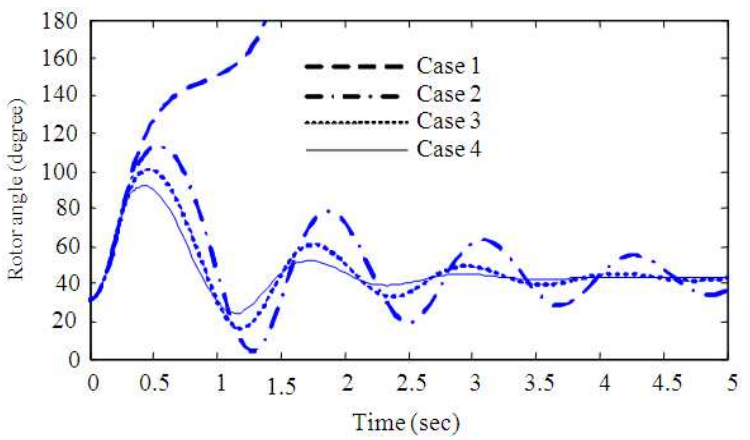

Fig. 4: The swing curve of the system with various gains of a TCSC and with the exact medium transmission for tcl $=210 \mathrm{~m} \mathrm{sec}$

Table 2: The maximum and minimum rotor angle of the system of

\begin{tabular}{lccc}
\multicolumn{2}{c}{ Fig. 4} & & \\
\hline CASE & $\mathrm{K}$ & $\delta_{\max }($ degree$)$ & $\delta_{\min }$ (degree) \\
\hline 1 & 0 & - & - \\
2 & 10 & 113.34 & 4.28 \\
3 & 20 & 100.90 & 16.21 \\
4 & 30 & 92.42 & 24.36 \\
\hline
\end{tabular}

\section{DISCUSSION}

It can be seen from the Fig. 3 that resistance of the line provides the improvement of the first swing stability. However, the resistance of the line provides the negative effect of the second swing. The shunt capacitance of the line doesn't affect on the swing curve whereas the resistance of the line can help the system improve the first swing stability of the system. The critical clearing time of the system without consideration of the resistance is around 190-191 m sec whereas with the resistance the actual critical clearing time is increased to $209-210 \mathrm{~m} \mathrm{sec}$.

The TCSC is also can improve transient stability of the power system. It can be observed in the Fig. 4 and Table 2 that without TCSC $(\mathrm{K}=0)$ the system for $\mathrm{tcl}=$ $210 \mathrm{~m} \mathrm{sec}$ is unstable. However, with $\mathrm{K}=10$ the system is stable with the maximum and minimum rotor angle 113.34 and 4.28 , respectively. The improvement is increased as the control gain is increased. With $\mathrm{K}=30$, the maximum and minimum rotor angle are 92.42 and 24.36 respectively.

\section{CONCLUSION}

This study investigated the effects of the Thyristor Controlled Series Capacitor (TCSC) on transient stability improvement of the Single Machine Infinite Bus (SMIB) system with the consideration of the exact medium transmission line model. The mathematical model was systematically derived by using the concept of the two-port network. This concept can help us to obtain mathematical model of the system in the simpler way.

The presented methods were tested and compared on various cases. It was found from the simulation results that the TCSC improve the transient stability performance both first swing stability and other swings whereas the resistance of the line provides the improvement of the first swing but not for the second swing. The shunt capacitance doesn't affect on the rotor angle of the SMIB system.

\section{REFERENCES}

Magaji, M. and M.W. Mustafa, 2009. Optimal thyristor control series capacitor neuro-controller for damping oscillations. J. Comput. Sci., 5: 980-987. DOI: $10.3844 /$ jcssp. 2009.980 .987

Li, K., J. Zhao, C. Zhang and W.J. Lee, 2010. Dynamic simulator for thyristor-controlled series capacitor. IEEE Trans. Ind. App., 46: 1096-1102. DOI: 10.1109/TIA.2010.2046283

Omar, R., N.A. Rahim and M. Sulaiman, 2010. New control technique applied in dynamic voltage restorer for voltage sag mitigation. Am. J. Eng. Applied Sci., 3: 42-48. DOI: 10.3844/ajeassp.2010.42.48

Padma, S. and M. Rajaram, 2011. Fuzzy logic controller for static synchronous series compensator with energy storage system for transient stability analysis. J. Comput. Sci., 7: 859864. DOI: $10.3844 /$ jcssp. 2011.859 .864

Prechanon, K., 2010. Application of interline power flow controller to increase transient stability of power system. J. Comput. Sci., 6: 1490-1493. DOI: 10.3844/jcssp.2010.1490.1493

Zarate-Minano, R., T.V. Custsem, F. Milano and A.J. Conejo, 2010. Securing transient stability using time-domain simulations within an optimal power flow. IEEE Trans. Power Syst., 25: 243-253. DOI: 10.1109/TPWRS.2009.2030369 